\title{
Matrix metalloproteinases and tissue inhibitors of metalloproteinases in synovial fluids from patients with rheumatoid arthritis or osteoarthritis
}

Yasuo Yoshihara, Hiroyuki Nakamura, Ken ’ichi Obata, Harumoto Yamada, Taro Hayakawa, Kyosuke Fujikawa, Yasunori Okada

Department of Orthopaedic Surgery, National Defence Medical College Y Yoshihara K Fujikawa

Department of Pathology, School of Medicine, Keio University H Nakamura Y Okada

Biopharmaceutical Department, Fuji Chemical Industries Ltd

K Obata

Department of Orthopaedic Surgery, Fujita Health University, Second Hospital

H Yamada

Department of Biochemistry, School of Dentistry, Aichi-Gakuin

University

T Hayakawa

Correspondence to: Dr Yasunori Okada, Department of Pathology, School of Medicine, Keio University, 35

Shinanomachi, Shinjuku-ku, Tokyo 160-0016, Japan Email:

okada@med.keio.ac.jp

Accepted for publication 10 January 2000

\begin{abstract}
Objective-Matrix metalloproteinases (MMPs) are expressed in joint tissues of patients with rheumatoid arthritis (RA) and osteoarthritis (OA). The objective of this study was to define the steady state levels of seven different MMPs and two tissue inhibitors of metalloproteinases (TIMPs) as well as the potential metalloproteinase activity in the synovial fluid (SF) to provide more insight into the role of MMPs in cartilage destruction in RA and $O A$.
\end{abstract}

Methods-Levels of MMP-1, MMP-2, MMP-3, МMP-7, МMP-8, МMP-9, МMP13, TIMP-1, and TIMP-2 in SF aspirated from knee joints of 97 patients with RA and 103 patients with $O A$ were measured by the corresponding one step sandwich enzyme immunoassays. Proteolytic activity of MMPs in these SFs was examined in an assay using $\left[{ }^{3} \mathrm{H}\right]$ carboxymethylated transferrin substrate in the presence of inhibitors of serine and cysteine proteinases after activation with $p$-aminophenylmercuric acetate (APMA). Destruction of RA knee joints was radiographically evaluated.

Results-Levels of MMP-1, MMP-2, MMP-3, MMP-8, and MMP-9 were significantly higher in RA SF than in OA SF. MMP-7 and MMP-13 were detectable in more than $45 \%$ of RA SFs and in less than $20 \%$ of OA SFs, respectively. Among the MMPs examined, MMP-3 levels were extremely high compared with those of other MMPs. Direct correlations were seen between the levels of MMP-1 and MMP-3 and between those of MMP-8 and MMP-9 in RA SF. Although the levels of $M M P-1$ and MMP-3 increased even in the early stage of RA, those of MMP-8 and MMP-9 were low in the early stage and increased with the progression of RA. Molar ratios of the total amounts of the MMPs to those of the TIMPs were 5.2-fold higher in patients with RA than in OA, which was significant. APMA-activated metalloproteinase activity in SF showed a similar result, and a direct correlation was seen between the molar ratios and the activity in RA SF.

Conclusions-Our results show that high levels of MMP-1, MMP-2, MMP-3, MMP-8, MMP-9, and TIMP-1 are present in RA SF and suggest that once these
MMPs are fully activated, they have an imbalance against TIMPs, which may contribute to the cartilage destruction in RA.

(Ann Rheum Dis 2000;59:455-461)

Destruction of cartilage is a common pathological feature in various arthritides, including rheumatoid arthritis (RA) and osteoarthritis (OA), and is a major cause of joint dysfunction, which is followed by impairment of the "quality of life" in those patients. Two pathways are known for the destruction of the cartilage. Firstly, an intrinsic pathway by which chondrocytes themselves degrade cartilage extracellular matrix (ECM) and, secondly, an extrinsic pathway by which tissues or cells other than chondrocytes, such as inflamed synovium, pannus tissue, and infiltrated inflammatory cells, break down the ECM of cartilage mostly through synovial fluid (SF). In both pathways, enzymic digestion of the ECM is ascribed to cartilage destruction.

Many proteinases belonging to all classes of proteinases are expressed in joint tissues of patients with RA and OA. Among them, however, matrix metalloproteinases (MMPs) are believed to have a key role in the joint destruction in the arthritides. ${ }^{1-3} \mathrm{MMPs}$, a gene family of neutral $\mathrm{Zn}^{2+}$ metalloproteinases, are composed of at least 18 members, which are classified into five subgroups of structurally related MMPs: (a) collagenases, including tissue collagenase (MMP-1), neutrophil collagenase (MMP-8), and collagenase 3 (MMP-13); (b) gelatinases such as gelatinase A (MMP-2) and gelatinase B (MMP-9); (c) stromelysins, including stromelysin 1 (MMP-3) and stromelysin 2 (MMP-10); (d) membrane-type MMPs (MT-MMPs), ${ }^{4-8}$ including MT1-MMP (MMP-14), MT2-MMP (MMP-15), MT3MMP (MMP-16), MT4-MMP (MMP-17), and MT5-MMP (MMP-24); and (e) other MMPs such as matrilysin (MMP-7), stromelysin 3 (MMP-11), metalloelastase (MMP12), MMP-19, ${ }^{9}$ enamelysin (MMP-20), ${ }^{10}$ and MMP-23. ${ }^{11}$ The enzymic activities of these MMPs are strictly controlled by inhibition with specific inhibitors - that is, tissue inhibitors of metalloproteinases (TIMP-1, TIMP-2, TIMP-3, and TIMP-4). ${ }^{212} 13$ Therefore, the balance between the amounts of MMPs and TIMPs in SF and local tissue may be a determinant of whether MMPs attack the cartilage ECM. 
MMP-1 and MMP-3 are produced by synovial lining cells in $\mathrm{RA},{ }^{14-16}$ whereas MMP-2 is produced by stromal cells in the sublining synovial layer. ${ }^{14}$ MMP-8 and MMP-9 are secreted by neutrophils, ${ }^{2}$ and MMP-9 is also produced by macrophages ${ }^{17}$ and synovial cells. ${ }^{18}$ In addition, the expression of these MMPs in chondrocytes has also been confirmed. ${ }^{19-22}$ On the other hand, various MMPs are present in arthritic SF, which are produced by the joint tissues and infiltrated inflammatory cells. Several groups have independently reported that the levels of MMP-1, MMP-3, MMP-8, MMP-9, and TIMP-1 in SF from patients with $\mathrm{RA}$ are raised compared with those from patients with OA or with posttraumatic knee injury. ${ }^{18} 23-28$ However, little or no information is available for the levels of other MMPs, such as MMP-2, MMP-7, MMP-13, and TIMP-2 in RA and OA SF. In addition, there are few reports that describe the actual levels of several MMPs in SF measured simultaneously in the same patients, and the relations between these levels and their potential enzymic activity or the disease progression of RA.

In this study we determined the steady state levels of MMP-1, MMP-2, MMP-3, MMP-7, MMP-8, MMP-9, MMP-13, TIMP-1, and TIMP-2 in the SF from patients with RA or $\mathrm{OA}$, and examined the correlation between the levels and potential proteolytic activity in the same samples.

\section{Methods}

PATIENTS

Ninety seven outpatients with RA and 103 outpatients with knee OA attending at the Department of Orthopaedic Surgery, National Defence Medical College Hospital, Tokorozawa were studied. Table 1 summarises the general and clinical characteristics of the patients and their knees.

Diagnosis of the patients with RA was based on the American College of Rheumatology 1987 revised criteria. ${ }^{29}$ They were further subdivided into three groups according to the method of Larsen et $a l^{30}$ based on the radiographic findings of femorotibial joints from which the SFs were aspirated; 17 patients

Table 1 Characteristics of the patients and their knees. Results are shown as mean (SD), (median), and range

\begin{tabular}{llll}
\hline Group $\left(n, F / M^{\star}\right)$ & Age (years) & $\begin{array}{l}\text { Disease duration } \\
\text { (years) }\end{array}$ & $\begin{array}{l}\text { Aspirated } S F^{*} \\
\text { volume }(\mathrm{ml})\end{array}$ \\
\hline RA & $57.6(12.1)$ & $13.0(9.3)$ & $17.0(13.5)$ \\
All & $(58)$ & $(11)$ & $(14.0)$ \\
$(97,74 / 23)$ & $22-82$ & $0.25-36$ & $2-65$ \\
Early stage & $46.0(15.4)$ & $5.0(3.9)$ & $19.4(12.4)$ \\
$(17,14 / 3)$ & $(51)$ & $(4.5)$ & $(17.0)$ \\
Middle stage & $22-68$ & $0.25-13$ & $3-45$ \\
$(57,41 / 16)$ & $59.0(10.2)$ & $13.1(8.7)$ & $18.6(15.1)$ \\
& $(59)$ & $(12)$ & $(18.0)$ \\
Advanced stage & $36-79$ & $0.5-36$ & $2-65$ \\
$(23,19 / 4)$ & $62.2(9.0)$ & $21.5(10.0)$ & $11.7(7.5)$ \\
OA & $(62)$ & $(21.5)$ & $(10.0)$ \\
All & $44-82$ & $3.5-42$ & $2-30$ \\
$(103,83 / 20)$ & $64.0(10.3)$ & $7.4(6.8)$ & $14.7(8.2)$ \\
& $(64)$ & $(5)$ & $(14.0)$ \\
\hline
\end{tabular}

$\star F=$ female; $M=$ male; $S F=$ synovial fluid. were in the early stage, which corresponds to the Larsen grade $0-I, 57$ patients in the middle stage corresponding to the Larsen grade II-III, and 23 patients in the advanced stage corresponding to the Larsen grade IV-V. All the patients with RA were treated with nonsteroidal anti-inflammatory drugs (NSAIDs). Fifty of these patients also received low dose steroid treatment (prednisolone, maximum $10 \mathrm{mg} /$ day). Some patients with RA were treated with disease modifying antirheumatic drugs - that is, sodium aurothiomalate (17 patients), auranofin (10), sulfasalazine (5), D-penicillamine (11), bucillamine (18), or mizoribine (4), and nine patients received methotrexate, either alone or in combination with steroid.

Knee OA was diagnosed by clinical and radiological evaluations based on the American College of Rheumatology criteria. ${ }^{31}$ Patients who presented with obvious joint injury or with generalised OA were excluded from the study. Fifty two patients with OA received various NSAIDs for knee pain.

Patients with RA or OA were not treated with intra-articular injection of steroids, chondroitin polysulphate or hyaluronic acid for at least one month before this study. SF was aspirated from the knee joints of patients with RA or OA under aseptic conditions as part of a therapeutic procedure, and stored at $-80^{\circ} \mathrm{C}$ before being used as described previously. ${ }^{25}$

MEASUREMENT OF MMP-1, MMP-2, MMP-3, MMP-7, MMP-8, MMP-9, MMP-13, TIMP-1, AND TIMP-2

Levels of MMP-1, MMP-2, MMP-3, MMP-7, MMP-8, MMP-9, MMP-13, TIMP-1, and TIMP-2 in SF were measured by the corresponding one step sandwich enzyme immunoassay (EIA) systems as described previously. ${ }^{27}{ }^{32-39}$ Briefly, the assay systems used two simultaneous immunoreactions of a solid phase monoclonal antibody and a horseradish peroxidase labelled Fab' fragment of another monoclonal antibody. The antibodies were raised against the zymogens (proMMPs) of human MMP-1, MMP-2, MMP-3, MMP-7, MMP-8, MMP-9, MMP-13, and bovine TIMP-1, or oligopeptides prepared from the amino acid sequence of human proMMP-7 and TIMP-2. The EIA systems for MMP-1, MMP-3, MMP-8, and MMP-13 measure both precursor and active forms of the MMPs, and the systems for these MMPs, except for MMP-8, detect the complex with TIMPs. ${ }^{27} 323437$ However, those for MMP-2, MMP-7, and MMP-9 measure only their precursor forms. ${ }^{33} 36$ The EIA system for TIMP-1 determines the whole amount of TIMP-1, including free TIMP-1 and the complexed forms with active MMPs and proMMP-9, ${ }^{36}$ but the EIA system for TIMP-2 detects free TIMP-2 and TIMP-2 complexed with active MMPs but not the complex with proMMP-2. ${ }^{39}$ Detection limits of these systems for MMP-1, MMP-2, MMP-3, MMP-7, MMP-8, MMP-9, MMP-13, TIMP-1, and TIMP-2 are $0.12,1.0,0.63$, $0.16,0.50,0.24,0.63,1.24$, and $6.30 \mathrm{ng} / \mathrm{ml}$, respectively. Values are calculated as $\mathrm{mol} / \mathrm{l}$ for 
Table 2 Levels of MMP-1, MMP-2, MMP-3, MMP-8, and MMP-9 in SF from knee joints of patients with rheumatoid arthritis and osteoarthritis. Results are shown as means (SD), (median), and range (nmol/l)

\begin{tabular}{llllll}
\hline Group & $M M P-1$ & $M M P-2$ & $M M P-3$ & $M M P-8$ & $M M P-9$ \\
\hline RA & $35.1(24.8)^{\star \star \star}$ & $28.7(8.3)^{\star \star \star}$ & $1980(1360)^{\star \star \star}$ & $13.2(18.6)^{\star \star \star}$ & $10.6(14.8)^{\star \star \star}$ \\
All & $(36.1)$ & $(28.2)$ & $(1853)$ & $(6.36)$ & $(5.77)$ \\
& $0.2-90.6$ & $14.8-52.2$ & $27-5384$ & $0.01-121.34$ & $0.02-65.54$ \\
Early stage & $38.5(20.3)^{\star}$ & $30.2(9.4)$ & $2150(1110)^{\star}$ & $6.08(8.83) \dagger$ & $3.91(5.94) \dagger$ \\
& $(37.6)$ & $(28.2)$ & $(2012)$ & $(2.25)$ & $(1.04)$ \\
Middle stage & $1.7-74.2$ & $16.2-52.2$ & $100-4254$ & $0.01-31.31$ & $0.02-24.25$ \\
& $39.8(24.1)^{\star \star}$ & $28.3(7.8)$ & $2180(1340)^{\star \star}$ & $14.9(17.2)$ & $12.7(16.2)$ \\
Advanced stage & $(40.5)$ & $(26.8)$ & $(2031)$ & $(8.61)$ & $(7.60)$ \\
& $0.4-90.6$ & $14.8-47.9$ & $121-5384$ & $0.01-86.11$ & $0.02-62.92$ \\
OA & $20.9(23.4)$ & $28.7(8.4)$ & $1350(1350)$ & $14.1(24.7)$ & $10.4(14.0)$ \\
All & $(16.6)$ & $(28.9)$ & $(801)$ & $(6.26)$ & $(8.39)$ \\
& $0.2-71.3$ & $14.8-49.3$ & $27-4024$ & $0.01-121.34$ & $0.02-65.54$ \\
& & & & & ND \\
\hline
\end{tabular}

${ }^{\star} \mathrm{p}<0.05$ versus corresponding values in advanced stage of $\mathrm{RA} ;{ }^{\star \star} \mathrm{p}<0.01$ versus corresponding values in advanced stage of $\mathrm{RA}$; $\star \star \star \mathrm{p}<0.001$ versus corresponding values in OA all.

$t \mathrm{p}<0.05$ versus corresponding values in middle and advanced stages of RA.

$\mathrm{ND}=$ not detected (see "Results").

the comparison using the following molecular weights: 51929 for proMMP-1, 70952 for proMMP-2, 52220 for proMMP-3, 27916 for proMMP-7, 51098 for proMMP-8, 78426 for proMMP-9, 51647 for proMMP-13, 20685 for TIMP-1, and 21755 for TIMP-2, which were calculated from their amino acid sequences. ${ }^{40}$

\section{MEASUREMENT OF CARBOXYMETHYLATED}

TRANSFERRIN-DEGRADING ACTIVITY IN SF

Carboxymethylated transferrin (Cm-Tf)degrading activity in SF was measured using $\left[{ }^{3} \mathrm{H}\right] \mathrm{Cm}-\mathrm{Tf}^{41} \mathrm{SF}$ samples (52 RA and $60 \mathrm{OA}$ ) were incubated with $1 \mathrm{mM} p$-aminophenylmercuric acetate (APMA) at $37^{\circ} \mathrm{C}$ for 18 hours to activate proMMPs. Ten microlitres of the activated samples was incubated with the same amount of $\left[{ }^{3} \mathrm{H}\right] \mathrm{Cm}-\mathrm{Tf}$ and assayed at $37^{\circ} \mathrm{C}$ for six hours in the presence of $2 \mathrm{mM}$ phenylmethane sulphonyl fluoride and $5 \mathrm{mM}$ $N$-ethylmaleimide to inhibit serine and cysteine proteinases. After the reaction, undegraded $\left[{ }^{3} \mathrm{H}\right] \mathrm{Cm}$-Tf was precipitated with trichloroacetic acid and centrifuged. The radioactivity in the supernatants was measured in a liquid scintillation counter. One unit of activity is defined as the amount of enzyme that degrades $1 \mu \mathrm{g} \mathrm{Cm}-\mathrm{Tf} / \mathrm{min}$ at $37^{\circ} \mathrm{C}$.

STATISTICAL ANALYSIS

Differences between the two diagnostic groups and among the radiographical stages of RA were analysed by the Mann-Whitney $U$ test for unpaired variables and the Kruskal-Wallis test, respectively. Correlations were sought using Spearman's rank correlation coefficient $\left(r_{\mathrm{s}}\right) \cdot \mathrm{p}$ Values less than 0.05 were considered significant.

\section{Results}

LEVELS OF MMP-1, MMP-2, MMP-3, MMP-7, MMP-8, MMP-9, MMP-13, TIMP-1, AND TIMP-2 IN KNEE SF FROM PATIENTS WITH RA OR OA

MMP-1, MMP-2, MMP-3, MMP-8, and MMP-9 were measurable by the EIA systems in more than $90 \%$ of RA SFs, and the mean (SD) concentrations were 35.1 (24.8), 28.7 (8.3), 1980 (1360), 13.2 (18.6), and 10.6
(14.8) nmol/1, respectively (table 2). Although MMP-1, MMP-2, and MMP-3 were also detectable in all the SF from patients with OA, MMP-8 and MMP-9 were detected only in fewer than $2 \%$ of the samples. The levels of MMP-1, MMP-2, MMP-3, MMP-8, and MMP-9 were significantly higher in patients with RA than in those with OA (table 2). On the other hand, MMP-7 and MMP-13 were measurable in $61 \%$ and $46 \%$ of SF from patients with RA, respectively, and in only $15 \%$ and $18 \%$ of the OA SF, respectively. The levels of MMP-7 (1.95 (3.61) nmol/1 $v 0.77$ (1.52) $\mathrm{nmol} / \mathrm{l}, \mathrm{RA} v \mathrm{OA})$ and MMP-13 (0.05 (0.04) $\mathrm{nmol} / 1 v 0.02(0.07) \mathrm{nmol} / \mathrm{l}, \mathrm{RA} v \mathrm{OA})$ in SF were extremely low compared with those of MMP-1, MMP-2, MMP-3, MMP-8, and MMP-9.

When the levels of MMP-1, MMP-2, MMP-3, MMP-8, and MMP-9 in SF in the different RA stages were compared, MMP-1 and MMP-3 were high even in the early stage and decreased significantly in the advanced stage (table 2). On the other hand, the levels of MMP-8 and MMP-9 were not high in the early stage, and appeared to increase with the progression of the RA stage (table 2). The levels of MMP-2 were not obviously changed.

Table 3 Levels of TIMP-1 and TIMP-2 in SF from knee joints of patients with rheumatoid arthritis and osteoarthritis. Results are shown as mean (SD), (median), and range (nmolll)

\begin{tabular}{lll}
\hline Group & TIMP-1 & TIMP-2 \\
\hline RA & & \\
All & $47.4(24.9)^{\star \star \star}$ & $7.22(1.76)$ \\
& $(40.5)$ & $(7.31)$ \\
Early stage & $14.2-121.3$ & $2.62-12.42$ \\
& $36.9(12.3)$ & $7.39(1.29)$ \\
& $(37.1)$ & $(7.31)$ \\
Middle stage & $17.5-67.0$ & $4.88-9.75$ \\
& $49.5(25.9)$ & $7.26(1.91)$ \\
Advanced stage & $(41.4)$ & $(7.41)$ \\
& $14.2-121.3$ & $2.62-12.42$ \\
& $50.1(27.0)$ & $6.97(1.62)$ \\
OA & $(43.9)$ & $(7.31)$ \\
All & $15.2-114.7$ & $2.67-10.07$ \\
& & \\
& $28.9(15.4)$ & $6.93(1.75)$ \\
& $(27.1)$ & $(6.81)$ \\
& $8.7-90.3$ & $3.50-12.97$
\end{tabular}

$\star \star \star \mathrm{p}<0.001$ versus corresponding values in OA all. 
Figure 1 Molar ratios of matrix metalloproteinases (MMPs) to tissue inhibitors of metalloproteinases (TIMPs),

carboxymethylated transferrin

(Cm-Tf)-degrading activity, and correlation between the molar ratios and the activity. (A) Molar ratios of total MMPs to total TIMPs were calculated as described in "Materials and methods". Bars indicate mean values in $R A$ and $O A$ synovial fluids (SFs). (B) $\mathrm{C} m$-Tf-degrading activity in $S F$ was measured after the p-aminophenylmercuric acetate (APMA) activation in the presence of serine and cysteine proteinase inhibitors as described in "Materials and methods". Bars indicate mean values in $R A$ and $O A$ SFs. (C) Correlation between the molar ratios and the Cm-Tf-degrading activity. Note a significant direct correlation $\left(r_{s}=0.580\right.$, $p<0.001$ ).
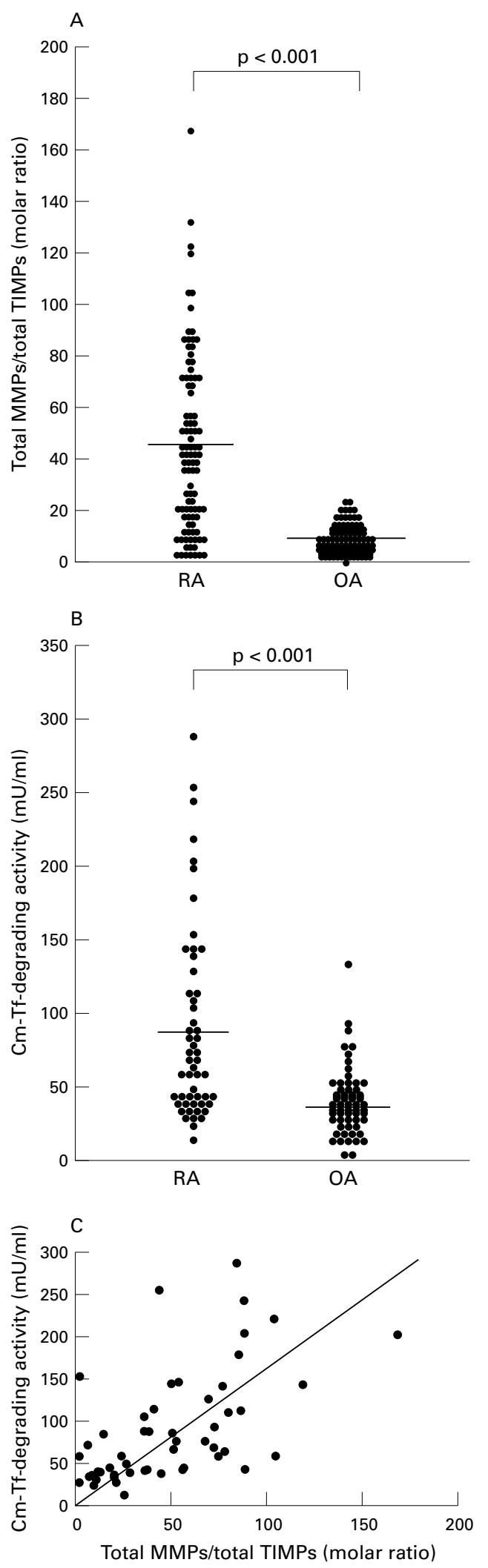

Both TIMP-1 and TIMP-2 were detectable in all RA and OA SFs. Although TIMP-2 levels did not differ between RA and OA SFs, the levels of TIMP-1 were significantly higher (1.5-fold) in RA SF than in the OA samples (table 3). The TIMP-1 levels also appeared to increase with progression of the RA stages (table 3), though they were not significantly different.

MMPS/TIMPS RATIO AND ENZYMIC ACTIVITY IN KNEE SF FROM PATIENTS WITH RA OR OA

Since the ratio of enzymes to their inhibitors is one of the critical factors for their proteolytic activities, the molar ratios of MMPs to TIMPs in SF from patients with RA and patients with OA were calculated. Figure 1A shows that the ratios in RA (44.3 (33.9), mean (SD) were significantly higher (5.2-fold) than those in OA (8.53 (5.53)). We further determined Cm-Tfdegrading activity in the presence of serine and cysteine proteinase inhibitors after the APMA activation, and found that the levels of activity in SF are significantly higher (2.2-fold) in patients with RA than those in patients with OA (fig 1B). Moreover, a significant correlation $\left(r_{\mathrm{s}}=0.580, \mathrm{p}<0.001\right)$ was observed between the molar ratio and the activity in SF from patients with RA (fig 1C), but such a correlation was not obtained with OA SF $\left(r_{\mathrm{s}}=0.287, \mathrm{p}=0.141\right)$ (data not shown).

RELATIONS BETWEEN THE LEVELS OF MMPS AND TIMPS IN SF FROM PATIENTS WITH RA OR OA Table 4 summarises the data on the relations between the levels of two MMPs in SF from patients with RA and patients with OA. Significant correlations were obtained between the levels of MMP-1 and MMP-3 in both RA $\left(r_{\mathrm{s}}=0.698, \quad \mathrm{p}<0.001\right)$ and OA $\left(r_{\mathrm{s}}=0.749\right.$, $\mathrm{p}<0.001)$. In addition, a highly significant correlation was observed between the levels of MMP-8 and MMP-9 in RA SF $\left(r_{\mathrm{s}}=0.896\right.$, $\mathrm{p}<0.001)$. There were also weak correlations between the levels of MMP-1 and MMP-2 in both RA $\left(r_{\mathrm{s}}=0.227, \mathrm{p}<0.05\right)$ and $\mathrm{OA}\left(r_{\mathrm{s}}=0.202\right.$, $\mathrm{p}<0.05$ ), and between the levels of MMP-2 and MMP-3 in OA SF $\left(r_{\mathrm{s}}=0.253, \mathrm{p}<0.05\right)$.

The levels of TIMP-1 correlated with those of MMP-8 and MMP-9 in RA SF $(p<0.001)$ (table 5). Significant correlations of the levels of TIMP-1 with those of MMP-1, MMP-2, and MMP-3 were also observed in $\mathrm{OA} \mathrm{SF}$, whereas such correlations were not present in patients with RA (table 5). On the other hand, levels of TIMP-2 in SF showed no significant correlation in either RA or OA.

\section{Discussion}

These studies have shown that among the seven different MMPs (MMP-1, MMP-2, MMP-3, MMP-7, MMP-8, MMP-9, and MMP-13) the steady state levels of MMP-1, MMP-2, MMP-3, MMP-8, and MMP-9 are significantly enhanced in SF from patients with RA compared with OA SF. The levels of MMP-7 and MMP-13 also seem to be higher in RA than in OA, as they were detectable in more than $45 \%$ of the RA SF samples but measurable only in fewer than $20 \%$ of the OA samples. Of these MMPs, the levels of MMP-3 were extremely high in both RA and OA SF. MMP-3 is capable of not only degrading many cartilage ECM components such as aggrecan but also of activating other proMMPs, including proMMP-1, proMMP-7, proMMP-8, proMMP-9, and proMMP-13. ${ }^{42}$ It is difficult 
Table 4 Correlation (Spearman's rank correlation coefficient $\left(r_{s}\right)$ ) between the levels of two MMPs in SF from patients with rheumatoid arthritis and osteoarthritis

\begin{tabular}{lcll}
\hline$R A$ & \multicolumn{1}{l}{$r_{s}$} & $O A$ & $r_{s}$ \\
\hline MMP-1 v MMP-2 & $0.227^{\star}$ & MMP-1 v MMP-2 & $0.202^{\star}$ \\
MMP-1 v MMP-3 & $0.698^{\star \star \star}$ & MMP-1 v MMP-3 & $0.749^{\star \star \star}$ \\
MMP-1 v MMP-8 & -0.131 & MMP-2 v MMP-3 & $0.253^{\star}$ \\
MMP-1 v MMP-9 & -0.143 & & \\
MMP-2 v MMP-3 & 0.112 & & \\
MMP-2 v MMP-8 & 0.039 & & \\
MMP-2 v MMP-9 & 0.094 & & \\
MMP-3 v MMP-8 & 0.043 & & \\
MMP-3 v MMP-9 & -0.011 & & \\
MMP-8 v MMP-9 & $0.896^{\star \star \star}$ & & \\
${ }^{\star}{ }_{\mathrm{p}<0.05 ; ~}{ }^{\star \star \star} \mathrm{p}<0.001$. & & &
\end{tabular}

${ }^{\star} \mathrm{p}<0.05 ;{ }^{\star \star \star} \mathrm{p}<0.001$

Table 5 Correlation (Spearman's rank correlation coefficient $\left(r_{s}\right)$ ) of the levels of TIMP-1 and TIMP-2 with the levels of MMPs in SF from patients with rheumatoid arthritis and osteoarthritis

\begin{tabular}{|c|c|c|c|c|}
\hline & \multicolumn{2}{|l|}{ TIMP-1 } & \multicolumn{2}{|l|}{$T I M P-2$} \\
\hline & $R A$ & $O A$ & $R A$ & $O A$ \\
\hline MMP-1 & 0.016 & $0.555^{\star \star \star}$ & 0.111 & -0.111 \\
\hline MMP-2 & 0.038 & $0.194^{\star}$ & 0.148 & 0.087 \\
\hline MMP-3 & -0.021 & $0.533^{\star \star \star}$ & -0.010 & -0.090 \\
\hline MMP-8 & $0.413^{\star \star \star}$ & $\mathrm{NE}$ & -0.054 & NE \\
\hline MMP-9 & $0.385^{\star \star \star}$ & $\mathrm{NE}$ & -0.092 & $\mathrm{NE}$ \\
\hline
\end{tabular}

to define the functional role of the high levels of MMP-3 in RA SF as it may exist mainly as a proenzyme. ${ }^{43}$ However, once proMMP-3 in RA SF can be activated on the surface of the articular cartilage, or within the cartilage after permeation from SF, this MMP may act as one of the most powerful MMPs for the loss of cartilage matrix through direct cleavage of cartilage ECM and activation of other proMMPs. The data of an early study on the collageninduced arthritis in MMP-3 deficient mice suggested that joint destruction is not altered by the expression levels of MMP-3. ${ }^{44}$ However, recent studies have shown that generation of an MMP cleavage site in aggrecan - that is, the FVDIPEN epitope, and degradation of cartilage collagen fibrils are strongly reduced in the MMP-3 deficient arthritic mice. ${ }^{45} 46$ In our study the MMP-3 levels were enhanced in the early and middle stages of RA and decreased in the advanced stage. Thus, these data, in addition to the findings from MMP-3 deficient mice, suggest that MMP-3 may have a central role in the initiation and progression of the cartilage destruction.

When soluble proteinases act in local tissues, ratios of the proteinases to their inhibitors are considered to be an important determinant. In our study the calculated values for molar ratios of MMPs to TIMPs in RA SF were 44 on average, suggesting the possibility of imbalance in favour of MMPs. However, the ratios do not simply indicate the generation of the degradative activity based on the MMP/TIMP imbalance, even if MMPs are fully active, as TIMP-3 and TIMP-4, which may be expressed in RA joint tissues, were not measured. In addition, $\alpha_{2}$ macroglobulin, a general inhibitor to proteinases, including MMPs, is present in RA SF. ${ }^{47}$ Thus we examined the total potential MMP activity in an assay using $\mathrm{Cm}$-Tf substrate by blocking the proteinase activities of other classes with inhibitors and activation of proM-
MPs in SF by the APMA treatment, and showed that the activity is detectable in all the RA samples. Furthermore, the molar ratios of MMPs to TIMPs in RA SF directly correlated with the levels of Cm-Tf-degrading activity. These data suggest the possibility that MMPs (that is, active MMPs plus proMMPs) in RA SF could become proteolytically active by overcoming the activity of TIMPs and other inhibitors, if proMMPs are fully activated. In OA SF, only MMP-1, MMP-2, and MMP-3 were mainly detected and their levels correlated well with that of TIMP-1, suggesting that the activities of these MMPs are well balanced by TIMP-1. However, the molar ratios of MMPs to TIMPs were $\sim 9$ on average in OA SF. Although definite direct correlation could not be obtained between the ratios and the activity, it is conceivable that the potential imbalance between MMPs and TIMPs is also present in OA SF, as low levels of APMA activated, Cm-Tf-degrading activity were detectable in all the OA samples.

It is notable that a highly significant correlation was present between the levels of MMP-1 and MMP-3 in both RA and OA SF. Coordinate mRNA expression of MMP-1 and MMP-3 has been shown in the synovium and articular cartilage by northern blotting ${ }^{48-50}$ and in situ hybridisation studies..$^{51-53}$ Wolfe et al insisted that cartilage is a source of MMP-1 and MMP-3 in SF from patients with RA or OA according to their data of the relative levels of MMP-3 mRNA expression to those of MMP-1 in chondrocytes. ${ }^{54}$ However, as articular chondrocytes are embedded in a large amount of ECM components, and thus the number of chondrocytes exposed to joint cavity is small, MMPs produced by chondrocytes may be a minor source in RA SF, if any. On the other hand, hyperplastic lining cells of RA synovium are faced to the joint cavity and produce a large amount of MMP-1 and MMP-3. ${ }^{14-16}$ Therefore, it is reasonable to think that the lining cells are a major cellular source of MMP-1 and MMP-3 in RA SF. This is supported by the finding that the production levels of MMP-1 and MMP-3 in RA SF are decreased in the advanced stage of RA, in which inactive fibrotic synovium is often found. There were weak but significant correlations between the levels of MMP-2 and those of MMP-1 and MMP-3 in RA or OA SF. This suggests that MMP-2 is also derived mainly from the synovial tissue. Compared with the levels of MMP-1, MMP-2, MMP-3, MMP-8 and MMP-9, MMP-7 and MMP-13 were present at extremely low levels in both RA and OA SF. MMP-7 expression has been shown in OA cartilage, ${ }^{55}$ but its production in RA or OA synovium is rare. ${ }^{145} \mathrm{MMP}-13$ is also highly expressed in OA cartilage, but its expression in RA synovium is negligible, ${ }^{57}$ though a previous study showed low expression. ${ }^{58}$ Thus these data suggest that the levels of MMPs and TIMPs in SF reflect the production mainly by synovial tissue, but not by articular cartilage.

MMP-8 and MMP-9 in SF are almost selective to RA, as they were measurable in more than $90 \%$ of RA SFs but detected in only $2 \%$ of 
OA SF. It is well known that the major cellular source of MMP-8 is neutrophils. ${ }^{259}$ Although a recent study has claimed that it is also expressed by synovial fibroblasts, ${ }^{60}$ our separate study showed that MMP-8 is undetectable in the culture media from RA synovial fibroblasts stimulated with interleukin $1 .^{56}$ Thus production of MMP- 8 by synovial cells, if any, is considered to be negligible. On the other hand, MMP-9 has been immunolocalised to various cells, including macrophages, giant cells, chondrocytes, and synovial cells as well as neutrophils in chronic synovitis and RA. ${ }^{14} 17$ However, a strong direct correlation between MMP-8 and MMP-9 in RA SF suggests the possibility that both MMPs are derived mainly from neutrophils infiltrated into synovial cavity. The levels of MMP-8 and MMP-9 in RA SF also correlated with those of TIMP-1. TIMP-1 is produced by the hyperplastic lining cells of RA synovium. ${ }^{14}{ }^{16}$ However, platelets contain a large amount of TIMP- $1,{ }^{61}$ and the platelet count in RA SF is high, with a correlation to the white blood cell count in the SF. ${ }^{62}$ Thus the source of raised levels of TIMP-1 in RA SF may be a mixture of platelets and synovial lining cells.

1 Nagase H, Woessner JF Jr. Role of endogenous proteinases in the degradation of cartilage matrix. In: Woessner JF Jr, Howell DS, eds. Foint cartilage degradation. New York: Marcel Dekker, 1993:159-85.

2 Nagase H, Okada Y. Proteinases and matrix degradation. In: Kelly WN, Harris ED Jr, Ruddy S, Sledge CB, eds. The text kook of rheumatology. 5th ed. Philadelphia: Saunders, 1996: book of rhe 41.

3 Firestein GS. Etiology and pathogenesis of rheumatoid arthritis. In: Kelly WN, Harris ED Jr, Ruddy S, Sledge CB, eds. The text book of rheumatology. 5th ed. Philadelphia: Saunders, 1996:851-97.

4 Sato H, Takino T, Okada Y, Cao J, Shinagawa A, Yamamoto $\mathrm{E}$, et al. A matrix metalloproteinase expressed on the surface of invasive tumor cells. Nature 1994;370:61-5.

5 Takino T, Sato H, Shinagawa A, Seiki M. Identification of the second membrane-type matrix metalloproteinase (MTMMP-2) gene from a human placenta cDNA library. MT-MMPs form a unique membrane-type subclass in the MMP family. J Biol Chem 1995;270:23013-20.

6 Will H, Hinzmann B. cDNA sequence and mRNA tissue distribution of novel human matrix metalloproteinase with a potential transmembrane segment. Eur J Biochem 1995; 231:602-8.

7 Puente XS, Pendás AM, Liano E, Velasco G, López-Otín C. Molecular cloning of novel membrane-type matrix metalloproteinase from a human breast carcinoma. Cancer Res $1996 ; 56: 944-9$

$8 \mathrm{Pei} \mathrm{D}$. Identification and characterization of the fifth membrane-type matrix metalloproteinase MT5-MMP. J Biol Chem 1999;274:8925-32.

9 Pendas AM, Knäuper V, Puente XS, Llano E, Mattei M-G Apte $\mathrm{S}$, et al. Identification and characterization of a novel human matrix metalloproteinase with unique structural
characteristics, chromosomal location, and tissue distribution. J Biol Chem 1997;272:4281-6.

10 Bartlett JD, Simmer JP, Xue J, Margolis HC, Moreno EC. Molecular cloning and mRNA tissue distribution of a novel matrix metalloproteinase isolated from porcine enamel matrix metalloproteinase isolate

11 Velasco G, Pendas AM, Fueyo A, Knäuper V, Murphy G, López-Otín C. Cloning and characterization of human $\mathrm{MMP}-23$, a new matrix metalloproteinase predominantly
expressed in reproductive tissues and lacking conserved expressed in reproductive tissues and lacking conserved
domains in other family members. J Biol Chem 1999;274: domains

12 Uría JA, Ferrando AA, Velasco G, Freije JMP, López-Otín C. Structure and expression in breast tumors of human TIMP-3, a new member of the metalloproteinase inhibito family. Cancer Res 1994;54:2091-4.

13 Greene J, Wang M, Liu YE, Raymond LA, Rosen C, Shi YE. Molecular cloning and characterization of human tissue inhibitor of metalloproteinase 4. J Biol Chem 1996;271: 30375-80.

14 Hembry RM, Bagga MR, Reynolds JJ, Hamblen DL. Immunolocalization studies on six matrix metalloproteinases and their inhibitors, TIMP-1 and TIMP-2, in synovia from patients with osteo- and rheumatoid arthritis. Ann from patients with osteo-
Rheum Dis $1995 ; 54: 25-32$.

15 Okada Y, Takeuchi N, Tomita K, Nakanishi I, Nagase H. Immunolocalization of matrix metalloproteinase 3 (stromelysin) in rheumatoid synovioblasts (B cell): correlation with rheumatoid arthritis. Ann Rheum Dis 1989;48: $645-53$.

16 Okada Y, Gonoji Y, Nakanishi I, Nagase H, Hayakawa T. Immunohistochemical demonstration of collagenase and tissue inhibitor of metalloproteinases (TIMP) in synovial lining cells of rheumatoid synovium. Virch Arch B Cell Pathol 1990;59:305-12.

17 Grillet B, Dequeker J, Paemen L, Damme BV, Opdenakker G. Gelatinase B in synovitis: immunolocalization with a monoclonal antibody. Br J Rheumatol 1997;36:744-7.

18 Ahrens D, Koch AE, Pope RM, Stein-Picarella M, Niedbala MJ. Expression of matrix metalloproteinase 9 (96-kd gelatinase B) in human rheumatoid arthritis. Arthritis Rheum tinase B) in human

19 Stephenson ML, Goldring MB, Birkhead JR, Krane SM, Rahmsdorf H-J, Angel P. Stimulation of procollagenase synthesis parallels increases in cellular procollagenase mRNA in human articular chondrocytes exposed to recombinant interleukin-1 $\beta$. Biochem Biophys Res Commun 1987;144:583-90.

20 Okada Y, Shinmei M, Tanaka O, Naka K, Kimura A, Nakanishi I, et al. Localization of matrix metalloproteinase 3 (stromelysin) in osteoarthritic cartilage and synovium. Lab Invest 1992;66:680-90.

21 Cole AA, Chubinskaya S, Schumacher B, Huch K, Cs-Szabo G, Yao J, et al. Chondrocyte matrix metalloproteinase-8. Human articular chondrocytes express neutrophil collagenase. J Biol Chem 1996;271: $1023-6$

22 Mohtai M, Smith RL, Schurman DJ, Tsuji Y, Torti FT, Hutchinson NI, et al. Expression of $92-\mathrm{kDa}$ type IV collagenase/gelatinase (gelatinase B) in osteoarthritic cartilage and its induction in normal human articular cartilage by interleukin 1. J Clin Invest 1993;92:179-85.

23 Walakovits LA, Moore VL, Bhardwaj N, Gallick GS, Lark MW. Detection of stromelysin and collagenase in synovial fluid from patients with rheumatoid arthritis and posttraumatic knee injury. Arthritis Rheum 1992;35:35-42.

24 Clark IM, Powell LK, Ramsey S, Hazleman BL, Cawston TE. The measurement of collagenase, tissue inhibitor of metalloproteinases (TIMP), and collagenase-TIMP complex in synovial fluids from patients with osteoarthritis and rheumatoid arthritis. Arthritis Rheum 1993;36:372-9.

25 Yoshihara Y, Obata K, Fujimoto N, Yamashita K, Hayakawa $\mathrm{T}$, Shimmei M. Increased levels of stromelysin-1 and tissue inhibitor of metalloproteinases- 1 in serum from patients with rheumatoid arthritis. Arthritis Rheum 1995;38:96975 .

26 Shinmei M, Kobayashi T, Yoshihara Y, Samura A. Significance of the levels of carboxy terminal type II procollagen peptide, chondroitin sulfate isomers, tissue inhibitor of metalloproteinases, and metalloproteinases in osteoarthritis joint fluid. J Rheumatol 1995;22(suppl 43):78-81.

27 Matsuki H, Fujimoto N, Iwata K, Knäuper V, Okada Y, Hayakawa T. A one-step sandwich enzyme immunoassay for human matrix metalloproteinase 8 (neutrophil collagenase) using monoclonal antibodies. Clin Chim Acta 1996;244:129-43

28 Sopata I, Wize J, Filipowicz-Sosnowska A, StanislawskaBiernat E, Brzezinska B, Maslinski S. Neutrophil gelatinase levels in plasma and synovial fluid of patients with rheumatic diseases. Rheumatol Int 1995;15:9-14.

29 Arnett FC, Edworthy SM, Bloch DA, McShane DJ, Fries HS, Cooper NS, et al. The American Rheumatism Association 1987 revised criteria for the classification of rheumatoid arthritis. Arthritis Rheum 1988;31:315-24.

30 Larsen A, Dale K, Eek M. Radiographic evaluation of rheumatoid arthritis and related conditions by standard reference film. Acta Radiol Diagn 1977;18:481-91.

31 Altman R, Asch E, Bloch D, Bole G, Borenstein D, Brandt $\mathrm{K}$, et al. Development of criteria for the classification and reporting of osteoarthritis: classification of osteoarthritis of the knee. Arthritis Rheum 1986;29:1039-49.

32 Zang J, Fujimoto N, Iwata K, Sakai T, Okada Y, Hayakawa T. A one-step sandwich enzyme immunoassay for human matrix metalloproteinase 1 (interstitial collagenase) using
monoclonal antibodies. Clin Chim Acta 1993;219:1-14.

33 Fujimoto N, Mouri N, Iwata K, Ohuchi E, Okada Y, Hayakawa T. A one-step sandwich enzyme immunoassay for human matrix metalloproteinase $2(72 \mathrm{kDa}$ gelatinase type IV collagenase) using monoclonal antibodies. Clin :91-103

34 Obata K, Iwata K, Okada Y, Kohrin Y, Ohuchi E, Yoshida S, et al. A one-step sandwich enzyme immunoassay for human matrix metalloproteinase 3 using monoclonal antibodies. Clin Chim Acta 1993;221:59-72.

35 Ohuchi E, Azumano I, Yoshida S, Iwata K, Okada Y. A onestep sandwich enzyme immunoassay for human matrix metalloproteinase 7 (matrilysin) using monoclonal antibodies. Clin Chim Acta 1996;244:181-98.

36 Fujimoto N, Hosokawa N, Iwata K, Shinya T, Okada Y, Hayakawa T. A one-step sandwich enzyme immunoassay for inactive precursor and complexed forms of human matrix metalloproteinase $9(92 \mathrm{kDa}$ gelatinase/type IV collagenase, gelatinase B) using monoclonal antibodies. Clin 年

37 Tamei H, Azumano I, Iwata K, Yoshihara Y, Lopez-Otin C, Vizoso F, et al. One-step sandwich enzyme immunoassays for human matrix metalloproteinase 13 (collagenase-3) using monoclonal antibodies. Connect Tissue Res 1998; 30:15-22. 
38 Kodama S, Iwata K, Iwata H, Yamashita K, Hayakawa T. Rapid one-step sandwich enzyme immunoassay for tissue inhibitor of metalloproteinases. An application for rheumatoid arthritis serum and plasma. J Immunol Methods 1990;127:103-8.

39 Fujimoto $\mathrm{N}$, Zhang J, Iwata $\mathrm{K}$, Shinya $\mathrm{T}$, Okada $\mathrm{Y}$, Hayakawa T. A one-step sandwich enzyme immunoassay for tissue inhibitors of metalloproteinase- 2 using monoclonal antibodies. Clin Chim Acta 1993;220:31-45.

40 Birkedal-Hansen $\mathrm{H}$, Moore WGI, Bodden MK, Windsor LJ, Birkedal-Hansen B, DeCarlo A, et al. Matrix metalloproteinases: a review. Crit Rev Oral Biol Med 1993; 4:197-250.

41 Okada Y, Nagase H, Harris ED Jr. A metalloproteinase from human rheumatoid synovial fibroblasts that digests connective tissue matrix components. J Biol Chem 1986;261: 14245-55.

42 Nagase $\mathrm{H}$. Activation mechanisms of matrix metalloproteinases. Biol Chem 1997;378:151-60.

43 Beekman B, van El B, Drijfhout JW, Ronday HK, TeKoppele JM. Highly increased levels of active stromeTeKoppele JM. Highly increased levels of active stromelysin in rheumatoid synovial fluid determined by a
fluorogenic assay. FEBS Lett 1997;418:305-9.

44 Mudgett JS, Hutchinson NI, Chartrain NA, Forsyth AJ, McDonnell J, Singer II, et al. Susceptibility of stromelysin 1-deficient mice to collagen-induced arthritis and cartilage destruction. Arthritis Rheum 1998;41:110-121.

45 van Meurs JBJ, van Lent PLEM, Holthuysen AEM, Stoop R, Singer II, Bayne EK, et al. Expression of the MMP-induced neoepitope FVDIPEN linked to severe cartilage damage: An essential role for stromelysin in antigeninduced arthritis. Transactions of 44th Orthopaedic Research Society, Rosemont: The Orthopaedic Research Society 1998:856.

46 Stoop R, van Meurs JBJ, Singer II, Bayne EK, Poole AR, Billinghurst $\mathrm{R}$, et al. The collagenase cleavage site in type II collagen colocalizes with the MMP-generated aggrecan neo-epitope VDIPEN inmurine antigen induced arthritis Transactions of 44th Orthopaedic Research Society,

47 Cawston TE, McLaughlin P, Hazleman BL. Paired serum and synovial fluid values of $\alpha 2$-macroglobulin and TIMP in and synovial fluid values of $\alpha 2$-macroglobulin and TIM

48 Frisch SM, Clark EJ, Werb Z. Coordinate regulation of stromelysin and collagenase genes determined with cDNA probes. Proc Natl Acad Sci USA 1987;84:2600-4

49 DiBattista JA, Pelletier J-P, Zafarullah M, Fujimoto N Obata K, Martel-Pelletier J. Coordinate regulation of matrix metalloproteinases and tissue inhibitor of metalloproteinase expression in human synovial fibroblasts. Rheumatol 1995;22(suppl 43):123-8.
50 Zafarullah M, Pelletier J-P, Cloutier J-M, Martel-Pelletier J. Elevated metalloproteinase and tissue inhibitor of metalloproteinase mRNA in hum

51 Gravallese EM, Darling JM, Ladd AY, Katz JN, Glimcher LH. In situ hybridization studies of stromelysin and collagenase messenger RNA expression in rheumatoid synovium. Arthritis Rheum 1991;34:1076-84.

$52 \mathrm{McCachren} \mathrm{SS}$. Expression of metalloproteinases and metlloproteinase inhibitor in human arthritic synovium. Arthritis Rheum 1991;34:1085-93.

53 Nguyen Q, Mort JS, Roughley PJ. Preferential mRNA expression of stromelysin relative to procollagenase and in situ localization in human articular cartilage. J Clin Invest 1992;89:1189-97.

54 Wolfe GC, MacNaul KL, Buechel FF, McDonnel J, Hoerrner LA, Lark MW, et al. Differential in vivo expression of collagenase messenger RNA in synovium and cartilage. Arthritis Rheum 1993;36:1540-7.

55 Ohta S, Imai K, Yamashita K, Matsumoto T, Azumano I, Okada Y. Expression of matrix metalloproteinase 7 (matriysin) in human osteoarthritic cartilage. Lab Invest 1998;78:79-87.

56 Takizawa $M$, Ohuchi E, Yamanaka H, Nakamura H, Ikeda $\mathrm{E}$, Ghosh P, et al. Production of tissue inhibitor of metalloproteinases-3 is selectively enhanced by calcium pentosan polysulfate in human rheumatoid synovial fibroblasts. Arthritis Rheum (in press).

57 Reboul P, Pelletier J-P, Tardif G, Cloutier J-M, MartelPelletier J. The new collagenase, collagenase- 3 , is expressed and synthesized by human chondrocytes but not by synoviocytes. J Clin Invest 1996;97:2011-19.

58 Wernicke D, Seyfert C, Hinzmann B, Gromnica-Ihle E. Cloning of collagenase 3 from the synovial membrane and its expression in rheumatoid arthritis and osteoarthritis. J Rheumatol 1996;23:590-5.

59 Chatham WW, Heck LW, Blackburn Jr WD. Liganddependent release of active neutrophil collagenase. Arthritis Rheum 1990;33:228-34

60 Hanemaaijier R, Sorsa T, Konttinen YT, Ding Y, Sutinen $\mathrm{M}$, Visser $\mathrm{P}$, et al. Metalloproteinase- 8 is expressed in rheu$\mathrm{M}$, Visser P, et al. Metalloproteinase- 8 is expressed in rheu-
matoid synovial fibroblasts and endothelial cells. J Biol Chem 1997;272:31504-9.

61 Cooper TW, Eizen AZ, Stricklin GP, Welgus HG. Platelet-derived collagenase inhibitor: characterization and subcellular localization. Proc Natl Acad Sci USA 1985;82: 2779-83.

62 Farr M, Wain WA, Salmon M, Hollywell CA, Bucon PA. Platelets in the synovial fluid of patients with RA. Rheumatol Int 1984;4:13-17. 